\title{
PA4ALL_Innovative Learning Methods for Education in Agriculture: An ICT Based Learning Programme for High Schools
}

\author{
Isidora Stojacic
}

PA4ALL addresses the topic of introducing precision agriculture tools in high schools specialised in agriculture, exploring the benefits of using the ICT in the field and encouraging high school students to uptake new trends and innovations. The aim is fostering the development of specific skills, greater connection to market needs and relevance for agriculture of the future. Improving the curriculum and fostering the adoption of ICT in schools to a larger scale application, the chapter presents the learning programme that scientists, trainers, and policymakers co-designed aiming at long term benefits to agriculture production and the labour market in Serbia.

\section{Introduction}

The case study of PA4ALL in the SISCODE project gathers the aforementioned in one scope. After conducting the interviews with the relevant actors, the team understood that the curriculum in high schools specialised in agriculture does not support the subjects related to ICT in general, nor do the school facility infrastructures support the implementation of ICT. Also, despite recent increase in the number of young people engaged in agriculture, Serbia still lags behind the countries in Europe. In the European Union, young farmers account for $8 \%$ of the total number of agricultural producers. In the Czech Republic and Poland, this percentage is even higher. In Serbia, however, less than 5 percent of young people are engaged in agriculture. By implementing precision agriculture tools into high school mandatory curriculum, PA4ALL together with BioSense will be able to achieve its long-term goal. Therefore, it can be said that the best solution for us to follow in SISCODE was the introduction of ICT subjects in agriculture courses, inclusion of ICT in

\section{Stojacic $(\bowtie)$}

BioSense Institute, University of Novi Sad, Novi Sad, Serbia 
schools specialised in agriculture, increase the awareness of the relationship between technology and agriculture.

\section{Ecosystem, Context and Challenge Addressed}

PA4ALL is an abbreviation for Precision Agriculture for All, which is also the main scope of the Living Lab, to introduce all the actors in the agriculture production chain to precision agriculture tools. The host organisation of PA4ALL is BioSense Institute [1], Institute for research and development of information technology in biosystems. Research and innovation at BioSense Institute is developed in a close interaction with farmers and the agrifood sector, government bodies, entrepreneurs and business community, international researchers, and citizens. BioSense collaborates to create a new generation of open innovations which will be readily used and which will bring benefits across the entire value-chain. As a meeting place for all relevant stakeholders, PA4ALL was established - the Living Lab for precision agriculture. This is the first Living Laboratory in Serbia and the first one in Europe to focus on precision agriculture. PA4ALL takes full advantage of inter-sectoral cross-fertilisation of ideas and offers possibilities to test ideas and prototypes in the real-world setting.

PA4ALL is located in Novi Sad, Serbia and is the only institution in the region focused on the topic of ICT in the agri-food sector. BioSense advances and integrates all that ICT can offer today-nanomaterials, low-cost miniature sensors, satellite imaging, robotics, big data analytics - to provide as much information as possible to the agricultural sector. The final goal of BioSense is to incorporate all efforts and results of various research groups into a unique BioSense integrated system for agricultural monitoring. This system will provide necessary data sets and create breakthroughs in the agrifood sector, not only in terms of increased efficiency, reduced pollution and monetary savings, but also in the way that farming is perceived and performed, making agriculture acceptable as a career choice to younger generations of farmers.

Co-creation represents a crucial method with all its tools for PA4ALL, since the Lab requires constant communication and feedback with the actors in the industry in order to facilitate the adoption of ICT in agriculture. Therefore, PA4ALL has its own ecosystem of farmers, SMEs operating in the field of agriculture, policymakers, schools specialised in agriculture where co-creation enables efficient interaction.

\section{Ecosystem and context}

The political context in Serbia in the past decades had brought a lot of turbulence to the society followed by frequent changes in relevant governmental institutions. Furthermore, as a society in transition, Serbia is facing the challenge of keeping up with the global challenges lacking the necessary technology and industry that would enable this process. However, previous socialist legacy provides Serbia with quality education in engineering professions, primarily electronics and mechanical engineering, It is exactly these fields that have in recent years become the pioneers 
of change influencing both policy and market and bringing ICT to the forefront of Serbia's export potential, talent pool and educational opportunities. A recent study conducted by the German-Serbian Chamber of commerce confirms that ICT is the fastest growing sector in the Serbian economy.

Given these developments, local policy context has also been changing. Traditionally, the lack of democratic institutions has led to a lack of bottom-up initiatives and little understanding for the co-creation process when talking about new initiatives and changes in the system. However, the growing potential of the ICT sector has led to the development of organisations and institutions with a common goal of working towards changing the institutional framework to increase the potential of the sector. ICT Clusters representing a group of companies, SMEs or start-ups formed in cities such as Novi Sad, Subotica, Nis, Belgrade and many others. Digital Serbia Initiative brings together banks, media companies, ICT companies, phone operators and acts in their best interest working on necessary policy changes.

In agriculture, more traditional approaches to policy are deployed. Most farmers form cooperatives and use these structures to influence crop prices, gain greater bargaining power when negotiating with the state, influence subventions etc. In this field, compared to ICT, serious co-creation and bottom-up policy initiatives have not yet happened.

As PA4ALL works at the intersection of the two respective fields, the assessment of the policy context through initial desk research as well as previous presence in the community directed us towards working more through the ICT community. Capitalizing on the current digital strategies, bottom-up initiatives and potential of ICT for Serbia's development, focusing the policy efforts here.

BioSense Institute is involved in multidisciplinary research performed in the fields of micro and nanoelectronics, communications, signal processing, remote sensing, big data, robotics and biosystems the team consulted the research groups on what kind of help can be provided to high schools specialised in agriculture in order to prepare its students for the future labor market. Remote sensing and GIS group gave us an excellent reference on which equipment should be provided to schools in order to help them learn more about the popular concept of Big Data analysis, which could be applied to agriculture as well. Since this group bases its research on processing, storage and retrieval of data acquired from multimodal sensors, and integration of large amounts of multimodal data acquired from different sources, the idea of organising training in high schools was born. The activities of the group include the development of systems for instant access to relevant data presented in ways which are the most informative to end users, such as GIS databases, which could be interesting to future professionals in agriculture.

\section{Challenge}

Farmers can no longer rely on timeworn coping strategies when all of their familiar benchmarks for making agricultural decisions are becoming increasingly less reliable. This raises the need for additional means such as ICT technologies applied in the field of agriculture. Many ICT in agriculture or digital agriculture interventions have been developed and tested around the world to help agriculturists improve their 
livelihoods through increased agricultural productivity and income, or by reducing risks.

PA4ALL started by introducing precision agriculture tools in high schools specialised in agriculture by presenting the benefits of using the ICT in agriculture and encouraging high school students to uptake new trends and innovations. After conducting desk research and interviews during the co-creation process with the stakeholders, PA4ALL concluded that the best solution would be to provide meteostations to one selected school, which will provide the best innovation idea related to ICT in agriculture. The meteostations will provide information such as soil humidity, air temperature, precipitation amounts, air humidity, wind direction through the BioSense internal platform-AgroSense which provides various data on personalised agriculture production. The final aim was to improve the curriculum in schools with this new module and change the adoption of ICT in schools on a larger scale, considering the notion that the younger agricultural household members are a demographic group that has demonstrated higher adoption rates of technology.

$P A 4 A L L$ focuses on connecting the citizens and the policymakers in order to incorporate the whole co-creation process. As PA4ALL works at the intersection of two fields, ICT and agriculture, the assessment of the policy context through initial desk research as well as previous presence in the community directed the team towards interacting more with some ICT community bodies using co-creation tools. The existing governmental strategies which are addressing the current policies that incentivise the implementation of ICT in education in Serbia (Digital Agenda) one could expect more innovation and mind set changes on a society level. Directly, co-creation activities brought positive examples to the policymakers on how the curriculum in schools could be improved and how the society could react to such educational system reforms. These encounters and moments of exchange took place during workshops, events, presentations, fair exhibitions and other events prepared for the local, regional and national policymakers involved in the project. Therefore, this initiated a set of indirect benefits such as digitalisation on a larger scale, not only in agriculture. Furthermore, by adding courses related to information technology to regular school curriculums encouraging children to understand the impact ICT has in various spheres not only in ones already known to them. It was possible to demonstrate that fields such as agriculture, industry, traffic, tourism and other branches of the economy benefit greatly from ICT and bring economic growth to individuals as well.

\section{The Co-creation Journey}

\section{Context analysis}

The Desk Research was undertaken in order to identify the crucial aspects lacking in the educational systems of Serbia related to ICT and agriculture. As aforementioned, firstly, materials used for this research were documents on Digital Strategy of Serbia and Strategy of development of information society in Serbia 2020. Furthermore, 
desk research uncovered existing initiatives promoting ICT education in schools and helped in developing next steps for conducting interviews.

Secondly, one school was selected as a reference point. Interviews were conducted with teacher Branislav Jovanovic and his students from a high school specialised in agriculture in Futog. The main questions addressed were related to their professional specialisation, additional workshops and seminars, training on ICT in agriculture and new equipment. After further analysing their needs, PA4ALL better understood the urgency of implementing ICT in the educational system of Serbia.

Finally, PA4ALL reached its network of innovators such as farmers, small and medium enterprises (SME's) and entrepreneurs, and asked them to provide their professional opinions on how schools specialised in agriculture could better address the current needs of the market and create better professionals in the field.

\section{Problem framing}

The analysed data helped to determine what are the crucial needs of schools to develop their curriculum activities and introduce new aspects in agriculture education.

The first established contact with schools around Serbia was at the Science Festival at the University of Novi Sad. The aim was to welcome the students attending schools specialised in agriculture to provide their ideas on new prototypes which could be developed, and which would help in solving some of the issues related to agriculture. After the ideas were presented at the science festival, which took place from May 18th until May 19th 2019, the best idea was selected and awarded with equipment which will bring ICT closer to students. The idea selected was called "SPRAYCONDI—a digital advisor for the reduction of errors in the application of pesticides' suggested by the high school specialised in agriculture from Futog, located in the suburbs of Novi Sad. "SPRAYCONDI" would help the farmer make the right decision regarding the reduction of drift and more efficient pesticide application, measurement of meteorological data at the site where the pesticide application is performed. The digitised data would also be transmitted via mobile network to a cloud or computer where a model for the impact of the pesticide application on biomass and the final yield will be generated. This data was supposed to be obtained at the meteorological stations on a regional level, which is why it has been decided to provide the meteostations to schools, so they could obtain the data locally form their own sources.

The idea provided by the school in Futog was evaluated as highly innovative and exactly the right way of thinking that was aimed to be induced in the heads of high-school children. The teacher who was working together with the team on this project was delighted to hear that the project will actually bring practical results to the school and that the children will be able to not only think of an idea but also be able to see how precision agriculture actually works in real life.

\section{Envisioning solutions}

The farmers community around BioSense provided information on activities which are necessary in order to improve the ICT-based knowledge inside the farmers community in Serbia in general. During the Annual ANTARES Workshop which took place from April 3rd until April 5th 2019., AgroSense-BioSense's platform 
was presented together with its main services designed for farmers who were invited to the workshop. The opportunity was taken to consult the farmers as users and other stakeholders regarding the plans for the SISCODE project and the idea of improving the educational system in agricultural specialised schools was strongly supported. The farmers provided advice on how to structure ideas regarding the needed equipment, how to address the students and it was pointed out how important it is for young professionals in the agricultural sector to use novel technologies such as the AgroSense platform, Big Data from meteostations, and others.

An additional source of information about the needed activities in schools which will improve the education of future professionals in the AgTech industry was the BioSense network, which comprises SMEs and start-ups. Since most of the entrepreneurs belonging to the network have a background in agriculture and ICT related sciences, they were an excellent reference point to suggest relevant changes and new ideas regarding the educational system. Since BIOS Institute is also involved in multidisciplinary research performed in the fields of micro and nanoelectronics, communications, signal processing, remote sensing, big data, robotics and biosystems consulting the research groups on what kind of help can be provided to high schools specialised in agriculture in order to prepare its students for the future labor market.

It was of crucial importance to gather ideas and info from experts who were already operating in the field of precision agriculture, both the end-users and the actual developers of the technologies. These actors were a perfect example of how two worlds would be combined, the ones who were the creator-researchers and the ones who were in the position to give complaints, suggest changes, innovations, and underline problems which occur in real life settings.

\section{Developing and prototyping}

In order to prototype the educational model designed by PA4ALL (BioSense Institute) a meteo station was installed on a piece of land in Futog, the city where PA4ALL (BioSense Institute) is located. The meteostation is now part of the agriculture equipment in the high school specialised in agriculture in Futog which enables the teachers and students to use precision agriculture tools themselves. Apart from installing the meteo station PA4ALL provided additional equipment such as laptops, video projectors and printers in order to help the school collect and manipulate meteorological data from the stations. PA4ALL also provided credentials to this high school digital platform AgroSense to allow them to evaluate the data such as precipitation, air or soil temperature. Finally, Vladan Minić, a researcher from PA4ALL explained to the teachers how to use AgroSense and demonstrated its benefits for agriculture production. The teachers and students showed deep interest in new technologies and in this educational model since they are aware of the necessity to improve the curriculum in schools by introducing precision agriculture as one of the subjects. They also understand that traditional agriculture production is a matter of the past and that precision agriculture is the future.

The policy officials underlined the main issue with this specific focus group, which is the fact that agriculture is not an interesting field for young people and that ICT 
can change the perception that young people have on agriculture - a crucial sector for any economy. Furthermore, the benefits of co-creation tools have been exploited in order to gather feedback and raise interest for our initiative. At the moment, an active dialogue with the responsible bodies is ongoing with the aim of paving the way for the necessary changes in the educational system and therefore improving the high school curriculum.

\section{Experimentation: Output, Transformations, Outcomes}

\section{Final concept}

The main solution offered in the SISCODE project is the new model design which could be implemented in high school curriculum on a national level and therefore would be applied in every school around Serbia. The services of AgroSense will be useful to schools since they will be able to see how a similar technology looks in practice. AgroSense has an option of mapping the parameters of the farm, with an option by which the images from the drones can be placed on the desired production plot, the maps of the conductivity of the soil obtained by the electro-magnetic probe, the yield maps of the combine and any other georeferenced images. By applying all these functions in a real context, our new learning module can be structured according to teachers and students identified needs and interests.

It is also important to mention that the formal and semi-formal bodies who focus on lobbying for advancement in ICT have been formed in recent years. This will support the sustainability of the project in the long run, since Serbia is heading towards a more digitised economy.

Co-creation tools were used when face-to-face meetings with the school directors during the meeting organised annually by the Ministry of Education where they discuss current issues and potential collaborations between schools. PA4ALL attended last year's meeting when the project initiative and the final goal was presented. The project idea came to be a source of appreciation from the school directors' side towards the organisation which made the working group proud and consider the next steps to be done. In the context of ensuring the project sustainability led to an idea to look for additional funds - national ones, which would help in suppling other schools, not only the one where the final solution was prototyped, with additional meteostations. Finally having succeeded in this activity at the moment it is aimed to implement the initial idea and install the new meteostations in other 8 schools around Serbia.

\section{Transformations triggered}

The PA4ALL team learned that co-creation in science withholds the potential for long-term positive results. Through co-creation the future potential of agriculture in Serbia can be shaped, just by interconnecting different important stakeholders. On an individual level co-creating can facilitate scientific research by providing precise directions and insights on a specific topic from an individual or organisation who is 
already involved in it. The flow of information is facilitated, lack of experiences does not impose a threat. On an organisational level, co-creating brings synergy, better organisational structure and deep engagement of the actors. PA4ALL understood that co-creating can bring together stakeholders from different levels of administration, therefore it could improve policies on city, region and even country level.

Recently, because of the COVID-19 situation, PA4ALL strives to engage the students using social media and online communication platforms such as Zoom or GoToMeeting, however since the schools were completely closed the case structure needed to be reorganised a bit.

\section{Lessons Learnt and Reflections}

PA4ALL detected that agriculture is significantly dropping in the numbers of people employed. Also, when compared to other high schools, those specialised in agriculture attract only $6 \%$ of yearly applicants, while grammary school enrolment is $26 \%$, IT schools' enrolment $11 \%$ and economic/law high schools' enrolment is $13 \%$. This is why it is aimed to make agriculture appealing for the youth of Serbia again. It has been directly demonstrated how precision agriculture tools can be used in the field and by promoting the use of advanced ICT solutions to high school children, they were enabled to adopt the use of precision agriculture in their own family agriculture production.

Additionally, it is planned to conduct other workshops with students and with teachers, which will be an extra activity aimed at the sustainability of the case study. It is planned to organise a summer school which will be linked to another project DATADRAGON $^{1}$ where high school children from all around Serbia will be able to learn more and try to use other precision agriculture tools such as robotic platforms, etc. [2]. Since the COVID-19 situation is in place at the moment there are some difficulties organising the events, but they are definitely in place for the future. Datadragon organises hackathons and events where people around the world come to learn more about Big Data in Agriculture and Precision Agriculture tools on a large scale.

Finally, when speaking about sustainability, it can be said that one of our main achievements is getting funds from national projects which will fund the meteostations being supplied to various schools around Serbia, which is already taking place as we speak, so other schools, not just the one in Futog will be able to use the model and the designed curriculum. More importantly, it will be able to influence more children to adopt precision agriculture tools. In addition, what marked this case study was the actual application of co-creation practices for the purpose of achieving the final goal. Throughout the entire course of the project various cocreation tools were applied such as interaction platforms, feedback gathering forms, various experimenting tools with the actors in the project, etc. All of the processes

\footnotetext{
${ }^{1}$ https://datadragon.eu/.
} 
used were designed by the team as well as the entire process in order to finalise the scope and change the curriculum, and was designed together with the school and the organisation's own community.

\section{References}

1. BioSens Institute. https://biosens.rs/. Last accessed 2021/03/12

2. Datadragon. https://datadragon.eu/. Last accessed 2021/03/12

Open Access This chapter is licensed under the terms of the Creative Commons Attribution 4.0 International License (http://creativecommons.org/licenses/by/4.0/), which permits use, sharing, adaptation, distribution and reproduction in any medium or format, as long as you give appropriate credit to the original author(s) and the source, provide a link to the Creative Commons license and indicate if changes were made.

The images or other third party material in this chapter are included in the chapter's Creative Commons license, unless indicated otherwise in a credit line to the material. If material is not included in the chapter's Creative Commons license and your intended use is not permitted by statutory regulation or exceeds the permitted use, you will need to obtain permission directly from the copyright holder.

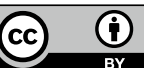

